\title{
Lendo rastos/tecendo traços/contando histórias: a configuração de uma trajetória nas Ciências Sociais, UFG
}

\author{
Telma Camargo da Silva \\ Doutora em Antropologia (City University of New York) \\ Professora na Universidade Federal de Goiás \\ Goiânia, Goiás, Brasil \\ telcamargos@gmail.com
}

\begin{abstract}
Resumo A partir de experiências subjetivas, este ensaio descreve e analisa as intersecções entre o Centro de Estudos da Cultura Popular (CECUP), os Cursos de Especialização em Antropologia e as Ciências Sociais da UFG. Situadas nos anos oitenta e noventa do século passado, as práticas discentes, docentes e de pesquisa aqui rememoradas informam projetos e temáticas de estudo nos anos que se seguiram. A argumentação do artigo, feita a partir das noções de rastos/marcas, de trajetória e de envelhecimento social, propõe que as histórias aqui configuradas como "uma" experiência ressoam a própria história das Ciências Sociais e compõem o painel dos traços aí desenhados.
\end{abstract}

Palavras-chave: trajetória, narrativa, memória, CECUP, Museu Antropológico (UFG).

\section{Introdução}

Life consists of retellings. (Bruner, 1996, p. 12)

W este texto, revisito os caminhos e os desvios que percorri en1 quanto professora e coordenadora da área de Francês, do Instituto de Ciências Humanas e Letras (ICHL), da Universidade Federal de Goiás, em dialógo com o Curso de Ciências Sociais, da mesma instituição. Retraço nesse trânsito, as experiências de pesquisa, formação e docência constituintes da minha identidade profissional de antropóloga e aponto as possíveis intersecções entre o local, o nacional e o internacional resultante das redes sociais advindas da prática profissional. Essa trajetória não linear é aqui entendida no sentido proposto por Bourdieu, como uma "série de posições sucessivamente ocupadas por um mesmo agente (ou mesmo grupo) num espaço que é ele próprio um devir, estando sujeito a incessantes transformações" (1996, p. 189). Assim, os elos e as conexões feitas pela evocação da experiência subjetiva do passado vivido não constituem uma memória institucional do Curso de Ciências Sociais mas, talvez, se coloquem como rastos $/ \operatorname{traços}^{1}-$ mar-

\footnotetext{
1. Em seu estudo sobre os sonhos dos aborígenes australianos, Barbara Glowczewiski (2005) utiliza a noção de "empreintes" (impressão), aqui traduzidas por "traços"/"rastos", para afirmar que estes sonhos encontram sua configuração em marcas impressas na superfície do território (dunas, fonte de água, rochedo) assinaladas pela passagem dos seres ancestrais que modelaram a superfície da terra. Nesse sentido, a autora traça a inter-relação entre as dimensões física e simbólica contida nos "traços" deixados pelos mais velhos na superfície
} 
cas a serem perseguidas e tecidas - para desvendar outros aspectos da relevância desse curso e de suas intersecções acadêmicas, teóricas e de campo disciplinar na constituição de profissionais que atuaram ou hoje atuam como docentes na Faculdade de Ciências Sociais.

Entre estes traços/rastos, a criação do Centro de Estudos da Cultura Popular (CECUP), nos anos oitenta do século passado e a realização de cursos de especialização em Antropologia promovidos pelo então Instituto de Ciências Humanas e Letras (ICHL) e pelo Museu Antropológico, nesse mesmo período, são aqui considerados. No entendimento desses "traços", considero importante situar rapidamente o contexto histórico, a estrutura administrativa e a espacialidade do então ICHL, aspectos estes que contextualizam o trânsito acadêmico e de compartilhamento de pesquisas entre professores/professoras e pesquisadores/ pesquisadoras das áreas das Ciências Sociais e Letras acima mencionadas.

O Instituto de Ciências Humanas e Letras (ICHL), criado pela Reforma Universitária de 1968 (Lei n. 5540/68), ${ }^{2}$ era constituído pelos cursos de História, Filosofia, Comunicação, Ciências Sociais e Letras, configuração esta que permaneceu durante os anos que se seguiram, até 1996, quando aconteceu o seu desmembramento em três unidades distintas: ${ }^{3} \mathrm{Fa}-$ culdade de Ciências Humanas e Filosofia, Faculdade de Letras e Faculdade de Comunicação. O ICHL era constituído por Departamentos e estes organizados em Áreas. As decisões pertinentes ao cotidiano acadêmico eram tomadas pelas reuniões de Colegiado que congregavam professores e professoras desses diferentes cursos. Pode-se dizer que o número relativamente reduzido de docentes possibilitava uma sociabilidade mais intensa entre os integrantes das diversas áreas de conhecimento e a produção conjunta de pesquisas e mesmo de publicações como ilustra a Revista do ICHL, criada em 1981 (Salles; Freitas, 1996, p. 12). A responsabilidade pela edição e a constituição do conselho editorial eram compartilhadas entre integrantes dos cinco cursos que compunham o então ICHL. ${ }^{4} \mathrm{~A}$ espacialidade configurada entre os chamados ICHL 1 e ICHL 2 concentrava em um prédio todos os gabinetes dos e das docentes e de outro, as salas de aula. Este ordenamento espacial também proporcionava maiores oportunidades para encontros e trocas. Desta forma, a minha trajetória acadêmica e de formação construída na intersecção entre as Letras e as Ciências Sociais está entrelaçada e tecida não só pela procura de um campo teórico que abrigasse as indagações levantadas pela experiência empírica, mas também pela própria dinâmica estrutural e histórica do ICHL.

Assim, este ensaio se constitui como expressão de "uma" experiência (Turner, 1986, p. 35), em que a narrativa tem uma intenção e uma lógica interna, "uma experiência estruturada", nos termos de Dilthey, que é trazer as minhas lembranças das experiências com/no Curso de Ciências Sociais - a partir dos traços/rastos deixados - e acionada pelo convite de colegas para participar dessa publicação. Resisti muito em aceitar o desafio de realizar este "trabalho da memória". 5 Demorei muito tempo imersa nas minhas lembranças até ser capaz de dar a elas uma coerência estrutural mínima que pudesse ser entendida como a "narrativa de uma experiência" (Turner, 1986, p. 35). E nessa narrativa se confundem sujeito e objeto dessas experiências, limites impossíveis de serem definidos. Em outras palavras, o texto é um exercício de retirar das vivências pessoais e subjetivas uma lógica ao mesmo "tempo retrospectiva e prospectiva, uma consistência e uma constância, estabelecendo relações inteligíveis" (Bourdieu, 1996, p. 184) para os e as leitoras que se situam em um outro tempo da vida universitária na UFG. Mas como parar o fluxo das lembranças se cada evento aciona outros tantos e cada indivíduo lembrado aciona inúmeros outros numa rede contínua que interliga pessoas, eventos e o tempo social? Mas o trabalho da memória foi realizado. A linha que costura os desvios e une os "traços" marcantes na minha trajetória é a da minha constituição como antropóloga em dialógo com as Ciências Sociais da

social (Bourdieu, 1996, p. 190). Eu me aproprio desta noção para dizer dos "traços", dos "rastos", deixados pelas experiências das pessoas que vivenciaram o ICHL nos anos 80/90 e que constituem a superfície social (Bourdieu) sobre a qual a memória se faz.

2. O ICHL teve sua origem na Faculdade de Filosofia, Ciências e Letras (FFCL), criada pelo Decreto n. 51.582 de 8 de novembro de 1962 . A FFCL em 1968, quando é desmembrada, concentrava até então os cursos de Letras, Ciências Sociais, Matemática, Física, Geografia, História e Jornalismo, e era a maior unidade da UFG em número de matriculados/as e de docentes. O ICHL foi a primeira unidade a ser instalada no Campus Samambaia, o que aconteceu em 1973.

3. Entendo que esta fragmentação se deu não somente pelas especificidades dos campos disciplinares que constituíam o então ICHL, mas também pelo aumento significativo do número de professores que já não podiam ser acomodados no espaço fisico e pela disputa de recursos alocados para o Instituto como um todo.

4. A título de ilustração, o v. I, n. 1, de julho, dezembro de 1981, teve como editor Sidney Valadares Pimentel (Comunicação); Gilka Vasconcelos Ferreira de Salles (História) como editora adjunta; Elísia Paixão Campos (Letras) como secretária e Servito de Menezes Filho (Ciências Sociais) como tesoureiro. Interessante assinalar, no que concerne ao argumento desenvolvido nesse artigo, que o Prof. Sidney Valadares passa a integrar o Departamento de Ciências Sociais, após seu doutorado em Antropologia na UnB.

5. Assinalo aqui a ação do sujeito no processo de elaboração dos sentidos do passado (Jelin, 2002) e, particularmente, na construção narrativa de "uma" experiência (Turner, 1986, p. 35). 
UFG e não obedece a uma ordem cronológica. As rememorações das quais esta narrativa é construída foram permeadas por emoções e afetividades vivenciadas nesse lugar do qual fala este ensaio mas cuja escrita foi higienizada dos afetos, como me parece requerer um texto de caráter acadêmico. Na tentativa de buscar uma lógica interna aos meus "desvios", organizei o ensaio em partes, onde situo o CECUP e os cursos de especialização em Antropologia cursados no ICHL na década de 1980 entendidos como rituais de passagem; a experiência como ativista indissociada da prática antropológica; e o diálogo entre a pesquisa produzida localmente e as redes nacionais e internacionais.

\section{CECUP: laboratório de pesquisa, constituição de acervo e construção de redes ${ }^{6}$}

O Centro de Estudos da Cultura Popular (CECUP) resultou do esforço conjunto de um grupo de professores e professoras de diferentes departamentos do então ICHL, mas não só, interessados no estudo do tema definido de forma bastante abrangente como cultura popular. Uma característica era compartilhada pelos integrantes desse grupo de jovens professores e professoras universitários/as: a interconexão entre a prática da docência e o ativismo político decorrente do processo de resistência à censura e à arbitrariedade no contexto histórico do movimento de redemocratização pelo qual passava o país. A militância compreendia o envolvimento na política universitária - com a intensa participação na Associação dos Docentes da UFG (ADUFG), criada em 21 de dezembro de 1978; a inserção nos movimentos sociais - como o feminista, ${ }^{7}$ no meu caso -, e o interesse na formação do Partido dos Trabalhadores.

A proposta inicial do CECUP foi redigida após várias reuniões realizadas durante o ano de 1980 e mais particularmente após o Seminário "A Questão da Cultura Popular", financiado pelo então Projeto Rondon e que contou com a presença do professor Renato Ortiz, então da Universidade Federal de Minas Gerais. Esta proposta foi aprovada pelo Conselho Diretor do ICHL, ${ }^{8}$ em 16 de setembro de 1981 (Portaria n. 016/81 do ICHL), que na sequência designou os professores Ione Maria de Oliveira Valadares, Telma Camargo da Silva e Luis Araújo Pereira para formarem a comissão responsável pela implantação do referido centro. O estatuto elaborado por esta comissão, e aprovado pelo Conselho Departamental do ICHL, definiu a sua vinculação diretamente a este conselho. Em outras palavras, isto significava que o CECUP não se ligava administrativamente a nenhum dos departamentos constitutivos do ICHL. Por esta razão, a sua coordenação alternou docentes dos Departamentos de Letras, Ciências Sociais, Geografia e Faculdade de Educação, evidenciando o seu caráter multidisciplinar ${ }^{9}$ tanto na abordagem da temática quanto na sua administração.

A linha articuladora desse centro de pesquisa foi a Cultura Popular, entendida como a cultura das classes subalternas. Para esta definição vale ressaltar a influência do antropólogo Carlos Rodrigues Brandão, então professor da Unicamp, que prestou consultoria ao grupo de pesquisadores em 1981 e 1983. O meu estudo sobre literatura de cordel, que resultou na minha dissertação de mestrado apresentada em 1977, na École des Hautes Études en Sciences Sociales (EHESS), sob a orientação de Jacques Leenhardt, coordenador do grupo de Sociologia da Literatura, influenciou também este entendimento da noção de cultura popular. ${ }^{10}$ As discussões em torno dessa noção subsidiaram o escopo de atuação do centro, como explicitado em seu Regulamento:

O CECUP se define como responsável pelo levantamento e estudo sistemáticos da Cultura Popular, principalmente no Estado de Goiás, através de pesquisas bibliográficas e de campo, bem como pela criação de acervo documental e pela manutenção de in-

6. Retomo nesta parte do ensaio a apresentação "CECUP - a experiência da transição", feita no Simpósio Especial "Antropologia em Goiás", organizado pela 25 $5^{\text {a }}$ Reunião Brasileira de Antropologia (25a RBA), que aocnteceu em julho de 2006, em Goiânia.

7. Em decorrência dos primeiros contatos com o movimento feminista na França, em fins da década de 1970, participei ativamente do cenário feminista goiano nos anos seguintes. A minha atuação no "Grupo Feminista de Estudos" e, posteriormente, no "Eva de novo" (Rocha; Bicalho; Faria, 1999), inclusive com a publicação do jornal Mariação são indissociáveis da minha atuação no CECUP. Esta inserção social conforma a organização de eventos como a mesa-redonda "A construção da identidade feminina", em 1987.

8. De acordo com a legislação vigente, o Conselho Diretor era presidido pelo diretor do instituto, cargo nesta época ocupado pelo prof. Flávio Rios Peixoto da Silveira.

9. A coordenação ora exercida de forma individual, ora coletiva, foi assumida por: Telma Camargo da Silva (1981-1983; 1989-1990); Clyce Louise Wiederhecker, Luís Araujo Pereira e Nei Clara de Lima (1983-1985); Clyce Louise Wiederhecker, Maria Tereza Canesin e Telma Camargo da Silva (1985-1986); Clyce Louise Wiederhecker (1987); Elza Chaves (1988) (Silva; Lima, 1990, p. 17).

10. A coordenação ora exercida de forma individual, ora coletiva, foi assumida por: Telma Camargo da Silva (1981-1983; 1989-1990); Clyce Louise Wiederhecker, Luís Araujo Pereira e Nei Clara de Lima (1983-1985); Clyce Louise Wiederhecker, Maria Tereza Canesin e Telma Camargo da Silva (1985-1986); Clyce Louise Wiederhecker (1987); Elza Chaves (1988) (Silva; Lima, 1990, p. 17). 
tercâmbio com organismos nacionais e internacionais congêneres. (CECUP, Regulamento, cap. I)

Contudo, ao longo dos anos e a partir das reflexões realizadas nas reuniões semanais, as temáticas foram se diversificando e a preocupação com o estudo de grupos socialmente minoritários ${ }^{11}$ ampliou o entendimento inicial centrado na categoria de cultura popular. Dentre as novas temáticas, citaria:

1) Religião Afro, com a organização, em 1985 da "Semana dos Orixás", em conjunto com a Associação dos Sociólogos do Estado de Goiás;

2) Relações de gênero, identidade e cidadania, com a realização, em 1987, do "Encontro sobre a questão da identidade" estruturado em: a) uma mesa redonda intitulada "A construção da identidade feminina" com a participação das professoras Mireya Suárez (UnB), com a comunicação "A desnaturalização do gênero", e Esther Jean Langdon (UFSC) abordando "Reprodução de papéis na escola"; b) uma palestra intitulada "Identidade e cidadania", proferida pelo Prof. Roberto da Matta (UFRJ).

3) Etnologia indígena, com participação do CECUP, 1985-1986, no "Projeto

Emergencial de Saúde na área Krahó” (Departamento de Ciências Sociais/CECUP/ICHL/Museu Antropológico/UFG/Instituto Goiano de Pré-História e Antropologia (IGPA) da Universidade Católica de Goiás (UCG)/Fundação Nacional do Índio (FUNAI) e Instituto Brasil Central (IBRACE). E também da organização da conferência "Condições de contato de um grupo Tupi no Amazonas: uma pesquisa em andamento", ministrada, em 1990, pelo Prof. Would Krack da Illinois University (Chicago, USA).

A produção de material para divulgação, em era pré-digital, implicava um lento processo de colagem ao qual muito tempo era dedicado. A realização de um panfleto comprendia várias fases entre elas a escrita manual das informações; a datilografia de um texto; a cópia xerox dos textos assim produzidos para posterior recorte e colagem manuais sobre uma folha de papel formato ofício. O resultado final ficava saturado de informações e com uma estética duvidosa como exemplificado na Figura 1.

Os projetos de pesquisa foram desenvolvidos com a participação de integrantes de diferentes departamentos do ICHL e também do Instituto de Química e Geografia (IQG) e da Faculdade de Educação. Citaria entre outros o Projeto "Biblioteca da Vida Rural Brasileira", realizado na cidade de Jaraguá-GO, e "Memória Social de Trabalhadores da Construção de Goiânia”. O primeiro, coordenado por mim, ${ }^{12}$ era originário do Ministério da Educação e Cultura, e integrava o Projeto de Ações Sócio-Educativas e Culturais para o Meio-Rural (PRONASEC/RURAL). Em Goiás, foi realizado através de uma parceria entre a UFG ${ }^{13}$ (Pró-Reitoria de Extensão) e Secretaria de Educação de Goiás. O projeto tinha como objetivo a valorização da cultura regional e popular com a produção de livros suplementares de leitura para a zona rural escritos a partir da interlocução com atores sociais locais. Este programa, voltado para a educação básica, representou uma experiência em que pesquisa acadêmica e as ações de extensão universitária estavam interligadas.

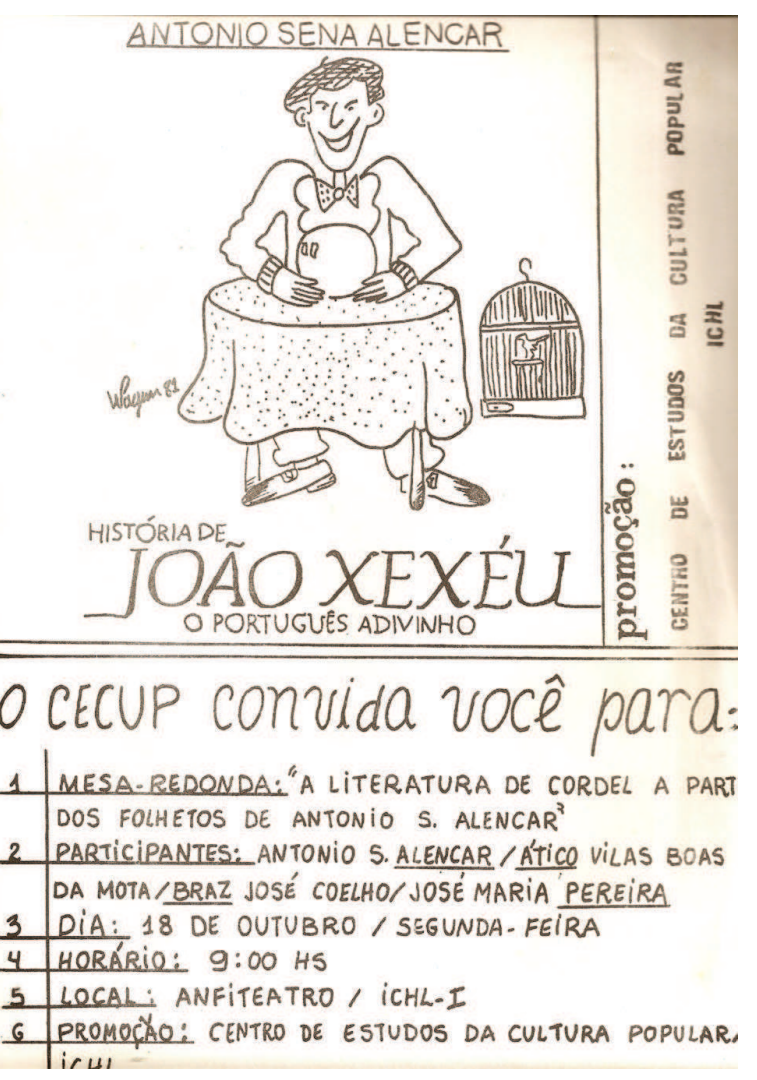

Imagem 1. Folheto para divulgação

Realização: Telma Camargo da Silva

11. Elaborado de outra forma, seria a problematização dos marcadores sociais da diferença, como raça, etnia, gênero e classe social, na constituição e manifestação das expressões culturais.

12. Integravam a equipe Ione Maria de O. Valadares, Luis A. Pereira, Maria Zaira Turchi e Margareth de Lourdes de O. Nunes (Departamento de Letras); Nei Clara de Lima e Mary lukie (Ciências Sociais); Maria Tereza Canesin (Faculdade de Educação); Clyce Louise Wiederhecker (Geografia - IQG); Sidney Valadares Pimentel (Comunicação) e Maria Luiza Nogueira Costa (Secretaria de Educação do Estado de Goiás).

13. A escolha da UFG e, particularmente do CECUP, para a realização do projeto em Goiás foi intermediada por Milton Cabral Viana, professor do ICHL no período de 1970-1978, então trabalhando no Ministério da Educação e Cultura, em Brasília. 
Na sua versão adotada pela CECUP, este projeto estabeleceu a área do ciclo do ouro em Goiás ${ }^{14}$ como seu espaço etnográfico e a cidade de Jaraguá como locus da pesquisa. Os três livros publicados em 1983 por este projeto (Histórias populares de Jaraguá (v. 1); Histórias populares de Jaraguá, Tereza Bicuda (v. 2); A Folia de Reis de Jaraguá) foram entregues para alunos e alunas das escolas da zona rural do município de Jaraguá e para todas as unidades públicas de ensino fundamental situadas na área urbana. Durante reuniões programadas para entrega das publicações nas fazendas do Córrego Grande e Bom Jesus, locais dos rituais da Folia de Reis, foram realizadas exposições fotográficas com imagens captadas durante a pesquisa. Os currais das fazendas foram usados como espaço expográfico. Além do registro das manifestçãoes culturais, esta pesquisa levantou importantes questões relativas à devolução dos resultados do estudo aos interlocutores nela envolvidos.

O segundo projeto, coordenado por Luis A. Pereira (Letras) foi integrado por Tânia M. Correa Camárcio e Elza Guedes Chaves (Ciências Sociais), Sidney Valadares Pimentel (Comunicação) e Clyce Louise Wiederhecker (Geografia-IQG). Utilizando a metodologia de construção de histórias de vida, a pesquisa resgatou aspectos da história de Goiânia através das perspectivas dos operários que aqui trabalharam na década de 1930.

Todos os projetos de pesquisa desenvolvidos no CECUP contaram com alunos e alunas dos cursos de Letras, Ciências Sociais, História e Biblioteconomia atuando como monitores e bolsistas (PRONASEC/SEC-GO/MEC; Bolsa de Iniciação Científica - CNPq) além da participação de estagiários. Nesse sentido, é importante ressaltar que este centro de pesquisa contribuiu também para a formação discente no contexto do então ICHL com a participação de alunos/as em suas atividades e a oferta de cursos na Semana de Atividades Complementares. Em 1988 ministrei o curso "A construção do gênero feminino"; 15 e no mesmo ano, em parceria com o antropólogo Marco Antonio Lazarin (Ciências Sociais), o curso "Imagem e antropologia: espaço para reflexão". Em 1990, Nei Clara ofereceu o curso "Culturas orais". Acredito que outra contribuição significativa do CECUP para os estudos na área das ciências humanas foi a constituição de um acervo sonoro e visual advindo das pesquisas realizadas e de uma biblioteca especializada na temática da cultura popular. Em 1990, este acervo foi transferido para o Museu Antropológico da UFG (Silva; Lima, 1990) e nos anos de 2013-2014 passa por tratamento técnico, sob responsabilidade de colegas do curso de Museologia da UFG. ${ }^{16}$

Além dos livros editados no âmbito do projeto "Biblioteca da Vida Rural Brasileira" (Silva; Canesin, 1983; Valadares; Lima, 1983a; Valadares; Lima, 1983b), foi criada a publicação Cadernos do CECUP, com circulação anual. Esta publicação objetivava disponibilizar para um público mais amplo os resultados das pesquisas e as reflexões realizadas pelos integrantes do centro de estudos. O número temático Memória social de trabalhadores da construção de Goiânia ilustra esta preocupação. O trabalho e a reflexão sobre os dados levantados nas diferentes pesquisas ultrapassaram os limites internos de produção intelectual do CECUP e seu acervo fomentou outros projetos. Em fins da década de 1980, Nei Clara de Lima elaborou o seu projeto para seleção de Mestrado na UnB a partir de dados levantados pela equipe do CECUP ( $A$ cidade de Jaraguá e a história de Tereza Bicuda: uma interpretação simbólica) e Marta Maria Lazarin para sua seleção na Unicamp (Tereza Bicuda: uma análise polifônica do sujeito). No caso de Nei Clara, o acervo foi retomado também na sua tese de doutorado Narrativas orais $e$ alegorias: uma poética da vida social, defendida em 1999, na UnB, sob a orientação de José Jorge de Carvalho.

A partir do CECUP, grupos de estudo informais foram organizados para leitura e discussão da obra de alguns autores escolhidos segundo as necessidades das pesquisas em andamento. Movido pelo interesse em aprofundar as reflexões sobre os conceitos de "liminaridade" e "rito de passagem", o grupo formado por mim, Nei Clara e Maria Dina N. Pinto (Ciências Sociais) se reuniu em torno da obra de Victor Turner. Dinâmica similar agrupou Selma Sena, Marco Lazarin e Nei Clara (Ciências Sociais) para a leitura de Émile Durkheim, o que fomentou uma discussão em torno do conceito de "consciência coletiva". Interessante para situar o contexto da época é assinalar que só havia dois exemplares de Les formes élementaires de la vie religieuse disponíveis para estudo: o meu, em francês, e o da Nei, em espanhol. Embora alguns dos colegas nomeados acima não integrassem formalmente o CECUP, considero este centro como catalisador dessas pessoas e da formação desses grupos de estudo.

Dessa forma, entendo que todas estas experiências vivenciadas por docentes e discentes de diferentes departamentos do ICHL configuram o CECUP como

14. Para esta escolha, foi fundamental a leitura dos trabalhos do historiador Luis Palacín, professor do Departamento de História do ICHL, em especial a tese apresentada ao concurso de Livre Docência na UFG, publicada, em 1979, com o título de O século do ouro em Goiás.

15. Esse curso fazia parte de uma unidade maior intitulada "A mulher, a ciência e a literatura: sombra ou presença", ministrado conjuntamente com as professoras Eliana Gabriel e Helena Campos.

16. O estudo deste acervo integra o projeto "Tratamento Técnico e Disponibilização do Acervo Iconográfico e Documental do Museu Antropológico da Universidade Federal de Goiás", financiado pelo CNPq (outubro, 2103 e outubro 2014) e coordenado por Vânia Dolores E. de Oliveira e Vera Regina B. Wilhelm. 
um traço/um rasto - uma impressão - a ser lido na constituição da história das Ciências Sociais na UFG. Laboratório de pesquisa e espaço de discussão, o CECUP foi para alguns e algumas de seus integrantes um dos lugares onde o ritual de passagem para o campo da antropologia foi efetivado. Na minha trajetória, foi nesse "lugar"17 (Keith; Basso, 1996, p. 9), durante os anos oitenta, que as experiências subjetivas vivenciadas com os foliões dos Santos Reis na zona rural de Jaraguá, com as mulheres Krahó na Aldeia Rio Vermelho, e com as pessoas atingidas pelo Desastre Radioativo do Césio-137 informam e configuram muitas das temáticas sobre as quais tenho pensado e escrito, como abordarei mais à frente. Foi nesse lugar também que aprendi e pratiquei o trânsito na burocracia acadêmica advinda tanto da coordenação de projetos de pesquisa, como da condução de um centro de estudos e organização de eventos. Entendendo a inserção nos encontros acadêmicos como indissociáveis da construção da minha identidade de antropóloga, considero que foi também a partir desse lugar que adentrei as reuniões científicas nacionais na área das ciências sociais: em 1981, a primeira participação nos Encontros do Centro de Estudos Rurais e Urbanos (CERU), ${ }^{18}$ em São Paulo, coordenando, a convite de Renato Ortiz, uma mesa-redonda no seminário Discussão sobre a cultura brasileira; em 1982, o VI Ciclo de Estudos Interdisciplinares da Comunicação (INTERCOM), em São Paulo; em 1986, a minha primeira participação em uma Reunião Brasileira de Antropologia - a XV RBA, realizada em Curitiba; e, em 1987, a minha primeira experiência como participante do Encontro Anual da Associação Brasileira de Ciências Sociais (ANPOCS) - o XI Encontro - realizado em Águas de São Pedro, SP.

\section{Cursos de Especialização em Antropologia: outro rito iniciático na mudança de campo disciplinar e na construção da identidade profissional}

Durante os anos oitenta do século XX, a organização e realização de três cursos de especialização em Antropologia (respectivamente em1985, 1986 e 1987) ${ }^{19}$ pelo Museu Antropólogico da UFG, em parceria com o ICHL, ressoam a experiência interdisciplinar e a articulação de redes acadêmicas nacionais a partir do local, como vivenciada no CECUP. Nesse sentido, estes cursos são por mim entendidos como traços/rastos interseccionados que, articulados a outros, compõem a história da Antropologia no âmbito do Departamento de Ciências Sociais do ICHL. Na minha trajetória estes três cursos engendram, tanto como o CECUP, o meu ritual de passagem ${ }^{20}$ das Letras para a Antropologia. Se no CECUP, a experiência com o trabalho de campo configurou a necessidade teórica e subjetiva de mudança de campo disciplinar, já iniciada com o Mestrado em Sociologia da Literatura, foi como aluna desses cursos de especialização que a formação em Antropologia, segundo os cânones acadêmicos, foi iniciada.

O financiamento desses cursos foi feito com recursos provenientes do acordo firmado entre o Ministério da Educação e Cultura, o Banco Interamericano de Desenvolvimento e a UFG, o chamado Acordo MEC-BID III, assinado em 1983. Recursos proveninentes do Banco Interamericano do Desenvolvimento já haviam financiado a construção de prédios no campus de Goiânia e subsidiado, em parte, o Programa de Interiorização da UFG, com a construção do campus de Catalão. Além da edificação de prédios, esse acordo tinha também como "intenção geral apoiar inciativas de ensino, pesquisa e extensão" (UFG Afirmativa, 2009, p. 7-12). A criação dessas especializações em Antropologia atendia a uma necessidade de capacitação docente que, segundo o Pró-Reitor de Pesquisa e Pós-Graduação no período de 1978 a 1989, Prof. Joaquim Caetano de Almeida Netto, era emergencial principalmente na área de ciências humanas $(2009$, p. 11). Esta necessidade particularizou estes cursos de especialização em Antropologia da década de 1980 em relação aos que foram realizados posteriormente, voltados não mais para a capacitação dos docentes da UFG mas para

estimular a pesquisa científica em Antropologia Social com o objetivo de conhecer melhor a realidade da região e de suas populações; sistematizar e armazenar dados e documentos importantes para a com-

\footnotetext{
17. Lugar como uma experiência corporificada em que se fundem o "self", o espaço e o tempo.
}

18. O CERU, vinculado à Faculdade de Filosofia, Letras e Ciências Humanas, da Universidade de São Paulo, era, nessa época, coordenado por Maria Isaura Pereira de Queiroz, ex-aluna e assistente de Roger Bastide. Nessa reunião a que me refiro, lembro-me da presença de Carlos Rodrigues Brandão, Renato Ortiz e Eva A. Blay. Com esta última conversei sobre o movimento feminista em Goiás e sobre o jornal Mariação, publicado pelo Grupo Feminista de Estudos ao qual pertencia naquela ocasião.

19. Os dois primeiros foram coordenados pela museóloga Judite I. Breda e o terceiro pela socióloga Maria Dina N. Pinto, ambas do Departamento de Ciências Sociais (ICHL).

20. Da mesma forma, talvez eles se configurem também como rituais iniciáticos para outros colegas que após estes cursos realizaram mestrado e doutorado em Antropologia. Particularmente, eu me recordo de ter sido colega de Nei Clara de Lima no curso realizado em 1985 e de Manuel Ferreira Lima Filho, no curso de 1987. 
preensão das populações estudadas pela Antropologia Social. (Departamento de Ciências Sociais/Museu Antropológico, 1996)

Seguindo a perspectiva boasiana dos quatro campos da Antropologia, que configurou a prática antropológica no Museu Antropológico nesse período, ${ }^{21} \mathrm{O}$ primeiro destes três cursos - o de 1985 - apresentou uma grade curricular que contemplava a antropologia social, a etnolinguística, a arqueologia e a antropologia física. A composição do quadro docente refletia, por um lado, a participação das instituições consideradas, naquele momento, como as de excelência no fazer antropológico no Brasil: USP, Unicamp, Museu Nacional e UnB. Por outro, assinalava uma rede de interlocução nacional estabelecida a partir do $\mathrm{Mu}-$ seu Antropológico e expressava a liderança da profa. Edna Luísa Taveira, então diretora do Museu, ${ }^{22}$ na condução do processo de formação em Antropologia no âmbito do ICHL. Este posicionamento sem dúvida reverberou no curso de Ciências Sociais naqueles anos. No sentido de explicitar estas considerações, segue abaixo a grade curricular desse curso, intitulado Curso de Especialização em Antropologia: Métodos e Técnicas de Abordagem em Etnologia Regional:

- Antropologia: contexto político (Roberto da Matta, Museu Nacional, Rio de Janeiro)

- Antropologia física (Marília Alvim, Museu Nacional, Rio de Janeiro)

- Arqueologia: projeto Anhanguera - Goiás (Margarida Andreatta, USP, São Paulo)

- Cerâmica: contexto arqueológico (Silvia Maranca, USP, São Paulo)

- Mudanças climáticas e adaptações humanas (Veleda L. Albuquerque, Fundação Joaquim Nabuco, Recife)

- Agricultura pré-histórica (Marcos Albuquerque, Universidade Federal de Pernambuco, Recife)

- Antropologia dos índios brasileiros (Julio Cezar Melatti, UnB, Brasília) Paulo)

- Relações raciais (Oracy Nogueira, USP, São

- Levantamento de problemas na descrição linguística de um grupo indígena (Yonne de Freitas Leite, Museu Nacional, Rio de Janeiro)
- Descrição fonética (Mirian Matta Machado, UnB, Brasília)

- Cultura popular e movimentos sociais (Eunice R. Durham, USP, São Paulo)

- Conferências e seminários (Roberto Cardoso de Oliveira, Unicamp, Campinas)

- Estudo de comunidade: Projeto Tapuia de Etnologia Regional (Heldo Vitor Mulatinho, ICHL, UFG, Goiânia).

Centrados no campo da antropologia social, nos dois outros cursos foram trabalhados os tópicos de relações de gênero, ideologia, memória e etnologia indígena e antropologia urbana, através das disciplinas: Sociedade indígena (Alcida R. Ramos); Grupos indígenas brasileiros (Roque de Barros Laraia); A construção do gênero feminino (Mireya Suárez); Cultura popular: espaço e moradia (Ana M. Heye); Nova metodologia do trabatho comunitário da memória cultural (Waldisa Russo C. Guarnieri); Antropologia e ideologia (Gustavo Lins Ribeiro). No período de participação nesses cursos, a minha inserção no ICHL interligava o duplo papel de docente (Letras) e discente (Museu Antropológico, Ciências Sociais). Posteriormente, ao final dos anos oitenta, logo antes da minha licença para doutorado nos Estados Unidos, em 1991, o hibridismo ${ }^{23}$ foi se acentuando. Ao duplo papel de docente/discente foi acrescentada, em algumas ocasiões, a atuação docente nos dois departamentos. No segundo semestre de 1988, por exemplo, além das disciplinas ministradas no departametno de Letras, meu departamento de origem, trabalhei a temática "Discutindo o papel de gênero" no quarto ano de Ciências Sociais (Forum de Debates).

Entre os estudos realizados durante os dois cursos de especialização acima mencionados, aqueles feitos sob a supervisão de Mireya Suárez foram fundamentais para a problematização da pespectiva essencialista acerca da categoria "mulher" ou "feminino", presente até então em minhas reflexões. Esse novo direcionamento foi aprofundado em disciplinas sobre relações de gênero e sexualidade, cursadas no doutorado com as professoras Ida Susser, Leith Mullings e Shirley Lindenbaum, o que refletiu em artigos produzidos posteriormente, como o publicado na Revista do

21. As professoras Silvia L. B. Braggio, Lydia Poleck, Raquel A. Teixeira, Marita P. Cavalcante, Monica Veloso e Maria Sueli de Aguiar, do Departamento de Letras ( $\mathrm{ICHL}$ ), tiveram intensa atuação na área de etnolinguística, ou linguística indígena, do MA. Algumas das línguas estudadas foram Karajá, Krahó, Avá-Canoeiro e Xerente (SEKI, 1999, p. 280). Na área de arqueologia, assinalaria a participação das professoras Irmhild Wust e Dilamar Cândida Martins das Ciências Sociais (ICHL) e de Margarita Andreatta, do Museu Paulista/USP, através do convênio UFG/ USP, para execução, durante os anos de 1975 a 1985, do Projeto Anhanguera de Arqueologia - Goiás.

22. A etnóloga e museológa Edna Luísa Taveira foi diretora do Museu Antropológico no período de 1983-1993 e, posteriromente, de 1995 a 1997.

23. Esse carater híbrido entre as Letras e as Ciências Sociais na realização de pesquisa e na prática docente só é definido com meu retorno do Doutorado na City University of New York, quando sou transferida do Departamento de Letras para o de Ciências Sociais, em 1996, após solicitação encaminhada e aprovada pelos departamentos envolvidos. 
Museu Antropológico, intitulado "Relações de gênero e noções de poder: uma relação dinâmica nas sociedades da Melanésia" (Silva, 1998d). Os direcionamentos teóricos repercutiram também, em fins dos anos noventa, na orientação de trabalhos de alunos e alunas do curso de Ciências Sociais. Citaria entre outros, a monografia de Moisés Lemos, defendida em 1999, no Curso de Especialização em Antropologia Social, intitulada Lenços azuis: representações de gênero e hierarquia nos rituais do movimento escoteiro, e os trabalhos de final de curso de Erlinda B. Pires, intitulado Relações de gênero e o emprego de novas tecnologias na indústria de confecção em Goiania (1997) e de Suzete Silva, A politização da homossexualidade: da privacidade aos cenários dos movimentos sociais (1998).

A ação compartilhada entre o Curso de Ciências Sociais e o Museu Antropológico na organização de cursos de especialização teve continuidade, posteriormente, com a realização, em 1996, do Curso de Especialização em Antropologia Social e, em 2000, com o de Especialização em Museologia ${ }^{24}$ dos quais participei como docente. Reflexo de um outro momento, ${ }^{25}$ em termos da qualificação dos e das antropológas que integravam a área de antropologia do departamento de ciências sociais, os docentes do curso realizado em 1996 eram todos da $\mathrm{UFG}^{26}$ ao contrário dos três outros que aconteceram na década de 1980 . Esta nova configuração e a realização da $25^{\mathrm{a}}$ Reunião Brasileira de Antropologia (25 RBA), em 2006, em Goiânia, ${ }^{27}$ em que os e as docentes da UFG participaram ativamente da organização do evento, são fatos que contribuíram para a criação do Programa de Pós-Graduação em Antropologia Social, ${ }^{28}$ em 2009. Nesse momento fundante, duas linhas de pesquisa articularam os projetos dos e das docentes e os trabalhos dos e das mestrandos/as: 1) Etnografia das ideias e dos repertórios culturais: etnografia dos saberes, valores e crenças; das instituições e das produções simbólicas; trajetórias de pessoas e de bens culturais; 2) Etnopolítica e processos de exclusão social: antropologia de processos de exclusão social, econômica, cultural e territorial, com ênfase na etnologia e etnopolítica de sociedades indígenas, negros, migrantes e grupos em fronteira.

\section{Academia, ativismo e circulação em redes acadêmicas}

$\mathrm{Na}$ década de 1980, enquanto integrante do CECUP/ICHL, tive duas experiências, entendidas de forma bastante abrangente como assessorias antropológicas, que foram definidoras do meu interesse pela Antropologia da Saúde e do meu projeto de pesquisa doutoral na City University of New York - Graduate Center (CUNY - GC) sob a orientação da Profa. Shirley Lindenbaum. ${ }^{29}$ A primeira, já mencionada anteriormente, foi a participação no Grupo de Trabalho de Saúde, constituído por uma equipe interdisciplinar, coordenada pelo antropólogo Marco Antonio Lazarin, que atuou na área indígena Krahó (1986-1987), particularmente na Aldeia Rio Vermelho (Lazarin; Silva, 1989). A segunda, a participação no Núcleo de Acompanhamento do Acidente Radiológico de Goiânia (NUAC), da Universidade Federal de Goiás, criado em 19 de outubro de 1987, pelo reitor Joel Pimentel de Ulhôa (UFG, Reitoria, Portaria n. 01086). Esse "acidente", categorizado pelas ciências sociais como desastre (Oliver Smith, 1996, 2002) ocorreu quando um aparelho de radioterapia abandonado foi coletado e aberto em 1987 por um grupo de pessoas. Este abandono e desmonte do equipamento médico causou a liberação do material radioativo césio 137 no espaço urbano de Goiânia e a contaminação de pessoas, animais, plantas e solos. Essa tragédia, analisada por mim como um evento crítico (Das, 1998 [1995]), é conhecida como o desastre com o Cs-137 de Goiânia (Silva, 1997, 2002).

Voltando à primeira experiência, iniciaria sua narração, dizendo que a criação do GT-Saúde para

24. Ministrei, juntamente com o antropólogo Marco Antonio Lazarin, a disciplina Antropologia. No programa constavam as temáticas de gênero, corporalidade e geração (ou, curso da vida como elaborado por Debert; Goldstein, 2000), que se constituíam como de interesse particular nas minhas reflexões. É deste período, por exemplo, a orientação da monografia de Suely Lima Pinto Memória e família: representação de um grupo de velhos e velhas, defendida em 2002, no Curso de Especialização em Museologia.

25. Em 1997, a área de Antropologia do Departamento de Ciências Sociais era composta por: Custódia Selma Sena; Dilamar Cândida Martins, Edna Luísa M. Taveira, Irmhild Wust, Maria Luiza R. Souza, Marco Antonio Lazarin, Nei Clara de Lima, Sidney V. Pimentel e Telma Camargo da Silva (Departamento de Ciências Sociais, 1997).

26. O corpo docente desse curso de Especialização em Antropologia Social era formado por Custódia Selma Sena; Irmhild Wust, Maria Luiza R. Souza, Marco Antonio Lazarin e Telma Camargo da Silva.

27. A coordenação local da 25a RBA foi compartilhada entre antropológos/as da Universidade Católica de Goiás (UCG) e da UFG.

28. A elaboração do projeto e o processo de implantação do mestrado acadêmico em Antropologia Social foram liderados pela Profa. Custódia Selma Sena e pelo Prof. Roberto Lima.

29. Lindenbaum é autora da etnografia Kuru sorcery: disease and danger in the New Guinea Highlands, que marcou os estudos no campo Antropologia da Saúde e da Doença nos EUA. Influência significativa na minha formação na CUNY-GC, ela pratica uma antropologia em que a produção acadêmica está interconectada com a prática política, no caso dela com a questão da Aids (Herdt; Lindenbaum, 1992). 
atuar na área Krahó e Xerente partiu de um apelo de lideranças indígenas para uma ação emergencial na área onde ocorria uma epidemia de tuberculose, gripe, sarampo e indícios de casos de câncer de útero. Esta demanda formulada pelos representantes indígenas e mediada pelo então delegado da $16^{\mathrm{a}}$ Delegacia Regional (DR) da FUNAI, em Araguaína, Fernando Schiavini, expressava as tensões vivenciadas na época sobre as questões de saúde de populações indígenas, não muito diferentes das existentes em 2014, vinte e oito anos depois. Nesse período, havia um monopólio tutelar da FUNAI, que centralizava os projetos de assistência, saúde e educação, alimentação e habitação marcado pelos direcionamentos advindos do período militar (1964-1985) na atuação do órgão (Santilli, 1991). Assim, esta demanda expressou a postura de autonomia das lideranças indígenas que, desiludidas com a não atuação do órgão, procuravam outros caminhos para a solução dos problemas. Marcou também o enfrentamento do funcionário que, não encontrando na FUNAI o respaldo para as demandas, procurou viabilizar parceria com outras instituições, no caso universitárias, o que provocou sua demissão da instituição.

Esta proposta de trabalho, contudo, não foi acolhida da mesma forma pelos gestores das duas instituições procuradas. Enquanto a UCG prontamente aceitou realizar a ação emergencial de saúde, a reitoria da UFG não acatou a solicitação das lideranças indígenas. Apesar disso, os antropólogos integraram o GT, o que representou de certa forma uma desobediência à decisão tomada pela instituição:

A proposta do Conselho Indígena do Norte de Goiás encontrou, institucionalmente, duas respostas. $\mathrm{Na}$ Universidade Católica foi acolhida imediatamente pelo seu Reitor, Prof. Pedro Wilson Guimarães. ${ }^{30}$ Na Universidade Federal, apesar do empenho dos Diretores do Instituto de Ciências Humanas e Letras (ICHL) e do Museu Antropológico, respectivamente professores Heldo V. Mulatinho e Edna Taveira, a proposta não foi aceita pela Reitora, Profa. Maria do Rosário Cassimiro. Todavia, a negativa institucional da UFG em participar formalmente da Equipe de Trabalho não impediu que tal se desse na prática: um grande número de professores e alunos da UFG compôs, ao final, a equipe de trabalho. (Lazarin; Silva, 1999, p. 10)

A ação antropológica envolveu três momentos: 1) Constituição e preparação, em Goiânia, da equipe composta por médico e estudantes de medicina, pedagogos, agronomos, enfermeiros, indigenista, estu- dante de psicologia e jornalista; 2) Intermediação em campo entre sujeitos portadores de distintos "idiomas culturais" (Cardoso de Oliveira, 1998, p. 23) no que se refere às conceptualizações de saúde, doença e corpo; 3) Intermediação entre equipe de saúde e mulheres Krahó na reunião coordenada por Hosana, a parteira indígena, na abordagem de questões em torno da sexualidade, plantas medicinais e também sobre a viabilidade de realização do exame ginecológico e coleta de material para exame onco-parasitário (Lazarin; Silva, 1988).

Do registro fotográfico realizado na Aldeia Rio Vermelho, produzi um ensaio intitulado Mulheres Mehin: um olhar fotograficamente amoroso, exposto no Museu Antropológico, UFG, em 1986, por ocasião do Dia Internacional da Mulher. Abaixo cartão-convite, em formato postal, criado para a divulgação do vento.

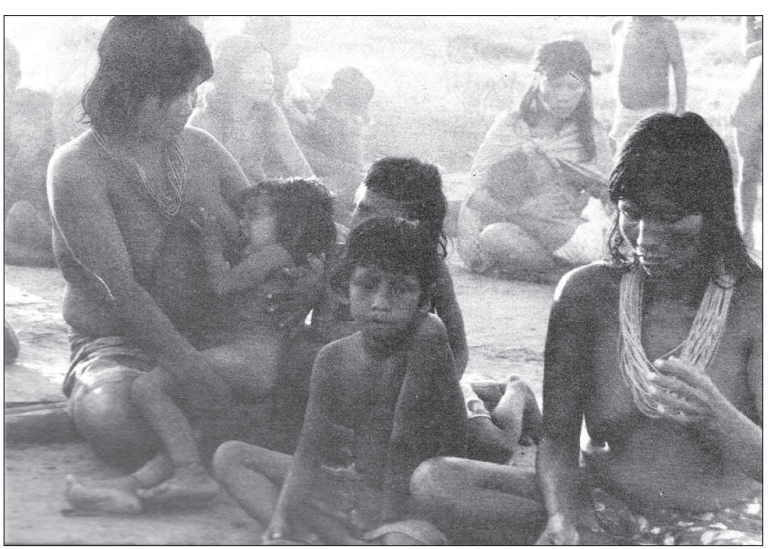

Imagem 2 - Frente do convite

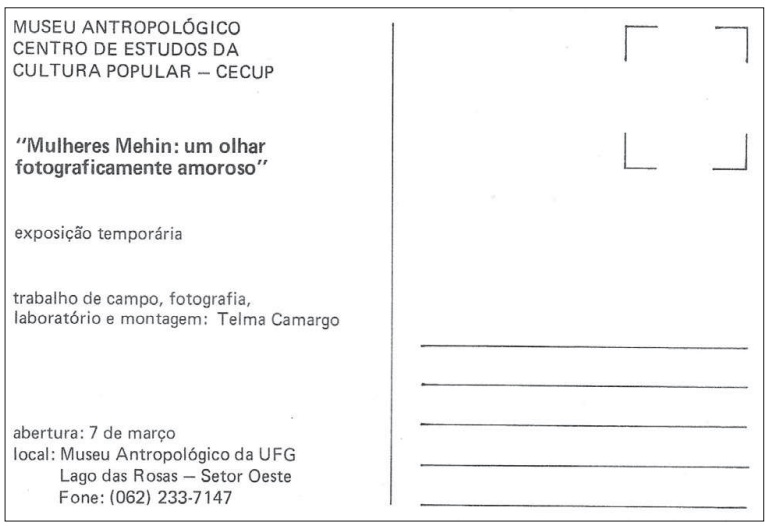

Imagem 3 - Verso do convite

Embora os resultados desse GT tenham sido avaliados positivamente, com o treinamento de uma equipe de saúde para atuação em área indígena e com

30. Que também foi professor do Departamento de Ciências Sociais (ICHL-UFG). Em face da recusa da UFG, a UCG garantiu os recursos econômicos e operacionais para a realização do GT. 
o desenvolvimento de ação emergencial de vacinação nas áreas Krahó e Xerente, a continuidade e os desdobramentos previstos pela assinatura de um acordo de cooperação entre UFG, UCG e a $16^{\mathrm{a}}$ DR da FUNAI para o desenvolvimento de ação contínua não aconteceram. As problematizações desta experiência e as sugestões decorrentes foram apresentadas na $1^{\mathrm{a}}$ Conferência Nacional de Proteção à Saúde do Índio, ocorrida no Ministério da Saúde, em Brasília, em 1986 (Lazarin; Silva, 1986). Nesse momento, eram realizadas as primeiras inciativas para a criação de um sistema de saúde indígena, que contou nas discussões com a participação intensa de antropológos de diversas instituições. Algumas das reflexões feitas por estes profissionais nessas reuniões resultaram nas mudanças efetivadas na Constituição de 1988 e na aprovação da Resolução n. 11/91 que criou a Comissão Interinstitucional de Saúde Indígena (CISI) do Conselho Nacional de Saúde.

Assim, o compartilhamento da experiência vivenciada nesse GT assinala, mesmo que de forma limitada e pontual, a participação do ICHL (Departamento de Ciências Sociais e CECUP) em algumas das discussões sobre políticas públicas de saúde para as populações indígenas. Em termos pessoais, além de apontar os caminhos do campo que mais tarde será configurado como o da Antropologia da Saúde e da Doença oportunizou, com a experiência etnográfica, a reflexão em torno da intersecção entre saúde, gênero, sexualidade e etnia, mais fundamentalmente entre relações de gênero e etnia. Esta articulação teria ressonância nos anos 2008-2011 com a minha participação na equipe de pesquisa do projeto Bonecas Karajá: arte, memória e identidade indígena no Araguaia. ${ }^{31}$ Embora este projeto esteja situado no campo dos estudos sobre patrimônio e cultura imaterial, as minhas reflexões articuladas em forma de artigos retomam a temática de gênero e etnia a partir da análise do modo de fazer e da produção de conhecimento das ceramistas karajá (Silva, 2014a, 2014b).

A segunda experiência de assessoria antropológica aconteceu no âmbito da resposta dada pela UFG ao desastre radioativo de Goiânia e problematizou o lugar das ciências sociais nas ações de intervenção no desastre e na discussão de temas considerados como de exclusividade das chamadas hard sciences, como o $\mathrm{da}$ radioatividade. Isto porque, embora houvesse na proposta de implementação das atividades do NUAC uma chamada para "a conjugação de esforços de to- dos os segmentos da comunidade" para enfrentar a crise vivida em 1987, que se traduzia "por substanciais sequelas para as atividades culturais, econômicas e sociais do Estado" (UFG, NUAC, 1987), a composição desse núcleo era formada predominantemente por físicos, biólogos e médicos. Cientes de que as ciências humanas tinham uma contribuição a ser feita, Marco A. Lazarin e eu redigimos um documento conclamando colegas para a criação, no NUAC, do setor de Ciências Humanas (Lazarin; Silva, 1987). Nesta mobilização fomos acompanhados por Clyce L. Wiederhecker e Elza G. Chaves ${ }^{32}$ e atuamos fundamentalmente junto à Associação das Vítimas do Césio 137, que se encontrava em fase de formalização e de cadastramento das pessoas afetadas. ${ }^{33}$

As ações do NUAC objetivavam: 1) monitoramento ambiental; 2) divulgação sobre os riscos e benefícios do uso pacífico de fontes de radiação procurando corrigir informações veiculadas de modo distorcido; 3) realização de seminários destinados à avaliação do acidente (sic); 4) realização de minicursos e de cursos de atualização para profissionais que utilizam fontes de radiação; 5) organização do acervo referente ao acidente (sic); 5) acompanhamento da população irradiada; 6) pesquisa sobre o acidente (sic) e suas consequências. Foi em atendimento a este último item que elaborei, junto com Marco Lazarin, um projeto de pesquisa intitulado "O acidente de Goiânia e seus impactos sociais" posteriormente reformulado para "Vítimas do Césio-137: uma leitura antropológica". Embora este projetos não tenham sido executados, considero as experiências vividas no NUAC como fundamentais para a minha pesquisa doutoral por ter propiciado uma reflexão sobre os primeiros momentos do impacto social do desastre e por ter possibilitado o acompanhamento das ações empreendidas pela UFG na administração da crise. Contudo, o mais importante para as minhas pesquisas futuras foi a relação que a partir do NUAC construí com as vítimas do desastre. Foi essa rede social que acionei, em 1996, quando do meu retorno de Nova York para a realização do trabalho de campo e redação da etnografia sobre o desastre de Goiânia (Silva, 2002). Assim, se a proposta de inserção das ciências humanas no NUAC foi motivada pela certeza de que poderíamos prestar uma assessoria no momento de contenção da crise, as pesquisas futuras realizadas por integrantes desse setor do NUAC, com a defesa de três teses de doutorado (Wiederhecker, 1998; Cha-

31. Projeto de pesquisa desenvolvido no Museu Antropológico da UFG, que subsidiou o registro da "Boneca Karajá" como Patrimônio Cultura Imaterial do Brasil, em 25 de janeiro de 2012. A equipe de pesquisa foi composta pelos antropólogos: Manuel Ferreira Lima Filho, Nei Clara de Lima, Rosani Moreira Leitão e Telma Camargo da Silva. Contou com participação de Núbia Vieira Teixeira e Michelle N. Rezende como assistentes de pesquisa.

32. A primeira do Departamento de Geografia e a segunda do Departamento de Ciências Sociais e ambas pesquisadoras do CECUP.

33. Os dados coletados durante este período como entrevistas orais gravadas integram o acervo do CECUP transferido para o Museu Antropológico da UFG. 
ves, 1998; Silva, 2002), reafirmaram a contribuição desta área do conhecimento para o entendimento dos eventos críticos, como os desastres radioativos, o que não era tão evidente nos anos oitenta, no Brasil.

Se a participação no NUAC, através da proposta de assessoria antropológica, representou uma forma de ativismo, tomar o desastre radioativo de Goiânia como tema de estudo foi motivado pelas emoções vividas naqueles anos de 1987-1998. Senti muito medo por ser moradora da cidade contaminada pela radiação e acreditava que a superação do pavor desapareceria à medida que adquirisse conhecimento sobre o desastre (Silva, 2002, p. 6). Isto me mobilizou para entrar em campo, estudar e tentar entender o que estava acontecendo. Resulta desta experiência o fato de nunca mais ter saído do campo: fui "contaminada" pelo tema. Replicando o movimento da radiação que vai se espalhando em ondas, minhas reflexões sobre o desastre de Goiânia foram incorporando novas temáticas com o transcorrer do tempo. Dos temas centrais trabalhados na tese de doutorado, como a análise dos processos narrativos e a produção das políticas da memória na constituição da identidade de vítima, passei à discussão de outras categorias. As análises decorrentes da permanência nesse campo configuraram estudos acerca da percepção de risco, construção de lugares, memória corporificada e processos de patrimonialização, entre outros (Silva, 1997, 1998a, 1998b, 1998c, 2001, 2002, 2003, 2004a, 2004b, 2005, 2007, 2009a, 2009b, 2012, 2014c).

A articulação entre estas várias temáticas é feita a partir das contribuições da Antropologia da Saúde e da Doença praticada por alguns antropólogos e antropólogas nos Estados Unidos, e parte da compreensão de que: 1) o sofrimento e as doenças não acontecem somente no corpo mas em um corpo que está no mundo ${ }^{34}$ (Good, 1994, p. 133); 2) existe uma intersecção entre a biologia humana, a construção cultural do conhecimento e as relações de poder (Lindenbaum; Lock, 1993). Esta perspectiva teórica é fundante do conceito de sofrimento social elaborado posteriormente (Kleinman; Das; Lock, 1996) e do qual me aproprio em muitos dos artigos que escrevi sobre o desastre de Goiânia. Estas elaborações teóricas de que compartilho implicam a análise dos contextos e das relações de força e poder em que os processos de adoecimento e sofrimento acontecem. É este referencial que informa, na minha perspectiva, os recortes empíricos e as análises elaboradas sobre as experiências e narrativas das pessoas afetadas pelo desastre de Goiânia.

As reflexões sobre o desastre de Goiânia, feitas no contexto da Antropologia da Saúde e da Doença assim definida, configurou novas formas de ativismo e ampliou a rede de articulação acadêmica na qual me insiro e, em decorrência, a do próprio Departamento de Ciências Sociais da UFG. Em termos do compromisso social com as populações estudadas, uma das "marcas" do fazer antropológico no Brasil segundo Alcida Ramos (1992a, 1992b), participei de audiências públicas sobre o desastre assumindo o papel de antropóloga testemunha (Silva, 2004b). Em outras ocasiões, integrei os temas do ativismo, justiça e das politicas públicas de saúde para as populações atingidas pelo desastre em comunicações feitas em eventos acadêmicos. Entre outras, citaria o painel Negotiating the Politics of Health (93rd Annual Meeting of the American Anthropological Association, Atlanta, USA,1994); a organização, em parceria com Hugo Benavides, da Fordham University (USA), do Fórum de Pesquisa $A$ pesquisa Antropológica e o Futuro das Populações com quem se Trabalha: uma reflexão crítica ${ }^{35}\left(24^{a}\right.$ Reunião Brasileira de Antropologia, Recife, 2004); a participação na mesa redonda Biossocialidades, instituições e espaços identitários em perspectiva (28 ${ }^{\mathrm{a}}$ Reunião Brasileira de Antropologia, São Paulo, 2012) ou, no GT Identidades, Biossocialidades, Espaços Sociais e Práticas Estatais (VI Congresso Brasileiro de Ciências Sociais e Humanas em Saúde, Abrasco, Rio de Janeiro, 2013). Com as discussões realizadas nesses dois últimos eventos, uma rede importante de interlocução foi construída principalmente com os colegas Carlos Guilherme O. do Valle, da Universidade Federal do Rio Grande do Norte, e com Sahra Gibbon, da University College London (UCL) do Reino Unido. Quanto à construção de redes acadêmicas, as reflexões centradas nos estudos de desastre, radiação, eventos críticos e memória traumática articularam o dialógo com um outro conjunto de colegas do qual fazem parte Cornelia Eckert (Universidade Federal do Rio Grande do Sul), Glaucia O. Silva (Universidade Federal Fluminense), Diego Zenobi (Universidade de Buenos Aires, UBA, Argentina) e Susann Ulberg Crisis Management Research and Training (CRISMART), Estocolmo, Suécia.

Em termos da inserção do Departamento de Ciências Sociais nas reflexões próprias à Antropologia da Saúde e da Doença, considero um marco importante a organização da mesa redonda "Antropologia da Saúde no Brasil: algumas perspectivas de trabalho", realizada em 1998, no Museu Antropológico da UFG dentro da programação do IV Fórum Goiano Sobre Cultura. Essa mesa contou com a participação de Paulo Cesar Alves, um dos organizadores da primeira coletânea publicada no Brasil com a temática da antropologia e saúde (Alves; Minayo, 1994); de Jane Russo e Annette Leibing, do Instituto de Me-

34. "... on the body in the world", no original.

35. Trabalhos apresentados nesse FP compõem o dossiê "Antropologia e responsabilidade social". Sociedade e Cultura, Goiânia, UFG, v. 6, n. 1 jan./jun. 2003 
dicina Social, da Universidade Estadual do Rio de Janeiro, UERJ. Nessa ocasião foi lançado o livro The Medical Anthropologies in Brasil, publicado na Alemanha e organizado por Annette Leibing, hoje professora da Universidade de Montreal, no Canadá. Como ilustração, cópia do convite para o evento:

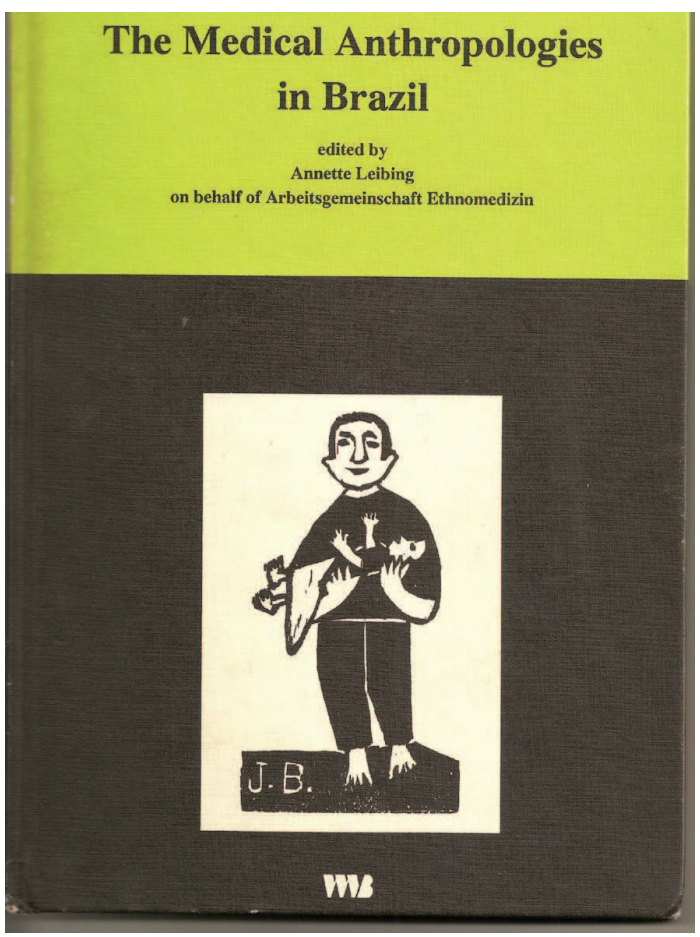

Imagem 4 - Frente do convite

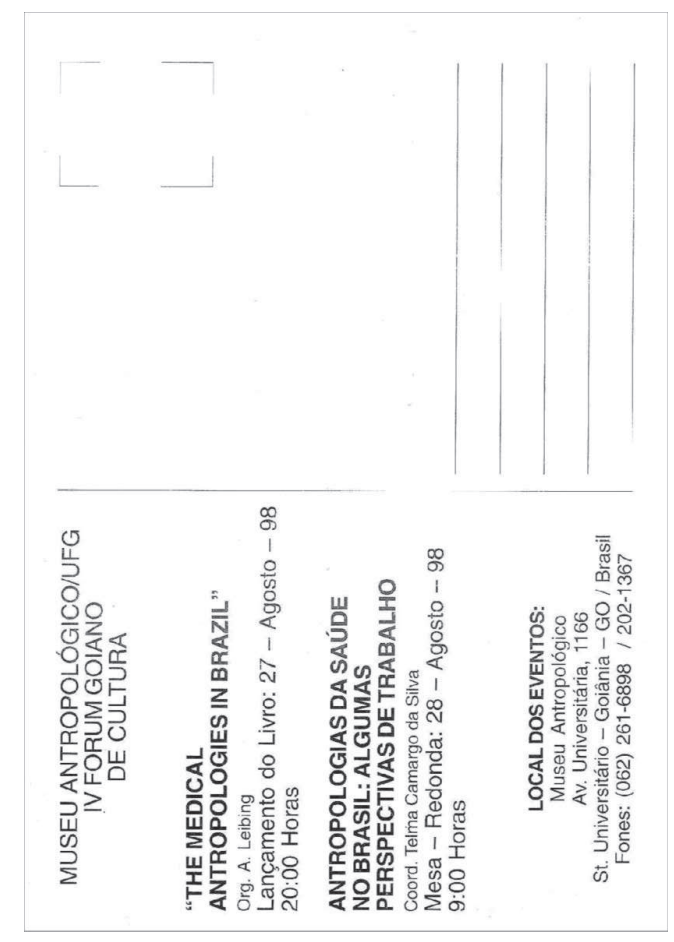

Imagem 5 - Verso do convite
Em fins dos anos noventa, estas reflexões ecoam no curso de Ciências Sociais com a inserção, em 1999, na disciplina do quarto ano intitulada "Forum", da unidade "Corpo, saúde e doença como construções socioculturais"; e, em 1997, no Curso de Especialização em Antropologia Social, com a inclusão nos "Seminários Temáticos em Antropologia Social” do tópico "Construção sociocultural da saúde e da doença: uma introdução". Nesta perspectiva de constituição de um campo específico de reflexão e de formação discente foram importantes também dois minicursos realizados como projetos de extensão: "Antropologias da saúde no Brasil: algumas perspectivas de trabalho" (1998) e "Antropologia do corpo, da saúde e da doença" (1999). Os estudos teóricos empreendidos nessas disciplinas direcionam alguns trabalhos de final de curso, como o de Hévila Perez Cruz intitulado Noção de pessoa e representação da doença entre os Krahó, apresentado em 1999, ou monografias apresentadas no Curso de Especialização em Antropologia, como a de Selma Santos, Menopausa - dor e libertação, defendida em 1999. Esta expertise construída no Departamento de Ciências Sociais motivou o convite para ministrar, em 1997, a disciplina "Doenças ocupacionais e ambientais: uma perspectiva antropológica”, no Curso de Especialização em Ciência e Educação (Faculdade de Educação) e, em 1999, no Curso de Especialização em Educação Ambiental (Instituto de Estudos Sócio-Ambientais). Estas reflexões repercutirão posteriormente no Mestrado em Antropologia Social da Faculdade de Ciências Sociais. Mas estas lembranças seriam objeto de outra narrativa e da tessitura de outra trajetória.

\section{Algumas considerações}

Consciente de que a memória articula a dualidade lembrança/esquecimento, tenho certeza de que muito daquilo que gostaria de pontuar ficará de fora. Em cinquenta anos, muitos rastos/traços foram impressos pelas experiências das diferentes pessoas cujas trajetórias configuram as Ciências Sociais na UFG. A escolha das marcas deixadas e o trabalho de tessitura feito na construção narrativa, como assinalado na introdução deste ensaio, foram empreendidos na tentativa de ordenar as experiências subjetivas do passado em “uma” experiência (Turner, 1986). Um exercício de ler, tecer e costurar traços/rastos foi realizado na busca de uma coerência interna através da qual uma das histórias vivida nas Ciências Sociais pudesse ser contada e lida. Assim, as lembranças trazidas pelo CECUP, pelos Cursos de Especialização em Antropologia dos anos oitenta, pelas experiências vividas na intersecção entre os departamentos de Letras e Ciências Sociais e entre eles e o Museu Antropológico, 
são um modo também de narrar a própria história da Antropologia no quadro das Ciências Sociais-UFG e, em decorrência, da Antropologia praticada em Goiás. Se nem sempre o envelhecimento social acompanha o envelhecimento biológico (Bourdieu, 1996, p. 190), no caso da trajetória objetificada neste texto estes dois envelhecimentos são indissociáveis. Talvez, no curso da vida, contar histórias seja uma das maneiras de manter o próprio fluxo desse curso. É isto que assinala Bruner evocado no início deste ensaio. A potencialidade narrativa dos eventos e a capacidade dos sujeitos em narrá-los são constituintes do próprio ato de viver. Considero então o trabalho de construção desse texto não só como uma contribuição ao painel das lembranças e histórias narradas sobre as Ciências Sociais da UFG mas, principalmente, como um exercício e uma maneira de viver o próprio envelhecimento.

\section{Referências}

ALVES, P. C.; MINAYO, M. C. de S. Saúde e doença: um olhar antropológico. Rio de Janeiro: Fiocruz, 1994. BOURDIEU, P. A ilusão biográfica. In: FERREIRA, M. de M.; AMADO, J. (Orgs.). Usos E abusos da história oral. Rio de Janeiro: FGV, 1996. p. 183-192.

BRUNER, E. M. Experience and its expressions. In: TURNER, W. V.; BRUNER, E. M. (Orgs.). The Anthropology of Experience. Urbana e Chicago: University of Illinois Press, 1996. p. 3-30.

CARDOSO DE OLIVEIRA, R. O trabalho do antropólogo: olhar, ouvir, escrever. In: ______. O trabalho do antropólogo. Brasília: Paralelo 15; São Paulo: Ed. Unesp, 1998. p. 17-35.

CECUP - Centro de Estudos da Cultura Popular. Regulamento. Goiânia, UFG, ICHL. 1981. (Manuscrito). CHAVES, E. G. Atos e omissões: o acidente com o Césio-137 em Goiânia. Tese (Doutorado) - Unicamp, Campinas, São Paulo, 1998.

DAS, V. Critical events: an anthropological perspective on contemporay India. Delhi: Oxford University Press, [1995]1998.

Debert, G. G.; GOldstein, D. M. (Orgs.). Politicas do corpo e o curso da vida. São Paulo: Sumaré, 2000.

DEPARTAMENTO DE CIÊNCIAS SOCIAIS. Perfil da área de antropologia (atividades em andamento). Goiânia: Ed. UFG, 1997. (Manuscrito).

DEPARTAMENTO DE CIÊNCIAS SOCIAIS/MUSEU ANTROPOLÓGICO DA UFG. Regulamento do Curso de Antropologia Social. Goiânia: Ed. UFG, 1996. (Manuscrito). FREITAS, L. C. B. F. de. UFG: tempo de crescer. UFG, Afirmativa, n. 3, p. 23-26, set. 2009. Disponível em: <htpps//WWW.yumpu.com/ptdocuments/view/ 12858929/afirmativa-ufg/27>. Acesso em: 18 set. 2014.

GLOWCZEWISKI, B.; HEALY, J. De L. Pistes de rêves: voyage en terre aborigènes. Paris: Éditions du Chêne, 2005.

GOOD, B. J. Medicine, rationality and experience: an anthropological perspective. Cambridge: Cambridge University Press, 1994.

JELIN, E. Los trabajos de la memoria. Madrid: Siglo XXI de España, 2002.

KLEINMAN, A.; DAS, V.; LOCK, M. Introduction.
In: KLEINMAN, A.; DAS, V.; LOCK, M. (Orgs.) Social suffering. Berkeley: University of Califórnia Press, 1996. p. IX-XXV.

LAZARIN, M. A.; SILVA, T. C. da. A intermediação antropológica no trabalho de saúde: observações sobre uma experiência entre os Krahó. Comunicação oral. Conferência Nacional de Proteção à Saúde do Índio. Ministério da Saúde. Brasília, 26-29 de novembro de 1986.

Proposta de trabalho para o Setor de Ciências Humanas - NUAC. Goiânia, UFG, 12 de setembro de 1987. (Manuscrito).

Saúde da mulher Krahó: observações sobre uma experiência de intermediação antropológica. Saúde em debate - Revista do Centro Brasileiro de Estudos em Saúde. Curitiba: Núcleo de Estudos em Saúde Coletiva (NESCO), p. 33-37, jan. 1988.

Os Krahó do Rio Vermelho: relatório de trabalho. Goiânia: Cegraf, 1989.

LEIBING, A. (Org.). The Medical Anthropologies in Brazil. Berlin: VWB, 1997.

LINDENBAUM, S. Kuru sorcery: disease and danger in the New Guinea Highlands. Mountain View, CA: Mayfield Publishing Company, 1979.

LINDENBAUM, S.; HERDT, G. (Orgs.). The time of Aids: social analysis, theory and method. Newbury Park; London; New Delhi: Sage Publications, 1992.

LINDENBAUM, S.; LOCK, M. (Orgs.). Knowledge, power and practice: the anthropology of medicine and everyday life. Berkeley: University of California Press, 1993.

OLIVER-SMITH, A. Anthropological research on hazards and disasters. Annual Review of Anthropology, n. 25, p. 303-328, 1996.

Theorizing disasters. Nature, power and culture. In: OLIVER-SMITH, A.; HOFFMAN, S. (Orgs.). Catastrophe \& culture: the anthropology of disaster. Santa Fé, New Mexico: School of American Research Press, 2002. p. 23-47.

PALACÍN, L. O século do ouro em Goiás. Goiânia/Brasília: Oriente/Instituto Nacional do Livro, 1979.

RAMOS, A. R. Sobre la utilidad social del conocimiento antropológico. Antropológicas. Mexico, Universidad 
Nacional Autônoma de México, p. 51-59, jul. 1991. O antropólogo como ator político. In: ARANTES, A. A. et al. (Orgs.). Desenvolvimento e direitos humanos: a responsabilidade do antropólogo. Campinas, SP: Ed. Unicamp, 1992, p. 155-174.

ROCHA, M. J. P.; BICALHO, E.; FARIA, G. J. de. Luta e resistência de mulheres em Goiás (1930-1993). Goiânia: Ed. UCG, 1999.

SAlleS, G. V. F. de; FREITAS, L. C. B. F. de. O mestrado em história das sociedades agrárias: uma abordagem histórica (1972-1995). História Revista, v. I, n. 2, p. 1-18, jul./dez. 1996.

SANTILLI, M. Os direitos indígenas na constituição brasileira. Povos indígenas 1987/1988/1989/1990. São Paulo: CEDI, 1991.

SEKI, L. A linguística indígena no Brasil. DELTA, São Paulo, v. 15. n. Especial, 1999. Disponível em: <www. scielo.br/pdf/delta/15nspe/4019.pdf>. Acesso em: 10 jul. 2014.

SILVA, T. C. da; BENAVIDES, O. H. (Orgs.). Dossiê: Antropologia e Responsabilidade Social. Sociedade $e$ Cultura, Goiânia, v. 6, n. 1, p. 7-84, jan./jun. 2003.

SILVA, T. C. da; CANESIN, M. T. (Orgs.). A Folia de Reis de Jaraguá. Goiânia: CECUP-ICHL-UFG. 1983.

SILVA, T. C. da; LIMA, N. C. Proposta de transferência do Centro de Estudos da Cultura Popular (CECUP) para o Museu Antropológico Universitário da UFG. Goiânia: Ed. UFG, nov. 1990. (Manuscrito).

SILVA, T. C. da. Biomedical discourses and health care experiences: the Goiânia radiological disaster. In: LEIBING, A. The medical anthropologies in Brazil. Berlin: VWB, Verl. Für Wiss. Und Bildung, 1997. p. 67-79. (Número Especial de Curare, 12).

. Política da memória: recompondo as lembranças no caso do desastre radiológico de Goiânia”. In: FREITAS, C. B. de (Org.). Memória. Goiânia: Ed. UCG, 1998a. p. 117-138.

Soldado é superior ao tempo: da ordem militar à experiência do corpo como lócus de resistência. Horizontes Antropológicos, Porto Alegre, ano 4, n. 9, out. p. 119-143, 1998b. (Número temático: Corpo, Doença e Saúde).

. Corpos em perigo: uma análise sobre percepção de risco em caso de desastre radiológico. XXII Encontro Anual da Associação Nacional de Pós-Graduação e Pesquisa em Ciências Sociais (ANPOCS), Grupo de trabalho: pessoa, corpo e saúde. Caxambu-MG. 27 a 31 de outubro. 1998c. Disponível em: <portal.anpocs.org/portal/índex. php?option>.

Relações de gênero e noções de poder: uma relação dinâmica nas sociedades da Melanésia. Revista do Museu Antropológico, v. 2, n. 1, p. 19-46, jan./dez. 1998d.

. Bodily memory and the politics of remembrance: the aftermath of Goiânia radiological disaster. High Plains Applied Anthropologists, v. 21, n. 1, Spring, 2001, p. 40-52. (Special number: Understanding Disasters and Catastrophes: An Anthropological Perspective).
Radiation ilness representation and experience: the aftermath of the Goiânia radiological disaster. Tese (Doutorado) - City University of New York - Graduate Center, New York, 2002.

Memória corporificada, marcas urbanas e esquecimento: a descontaminação simbólica no caso do desastre de Goiânia. VIII Reunião de Antropólogos do Norte e Nordeste (ABANNE). São Luís (MA), Brasil, $1^{\circ}$ a 4 de julho de 2003.

Desastre como processo: saberes, vulnerabilidade e sofrimento social no caso de Goiânia. In: LEIBING, A. (Org.). Tecnologias do corpo: uma antropologia das medicinas no Brasil. Rio de Janeiro: NAU Editora, 2004a. p. 201-225.

Os cientistas sociais no cenário político das sessões especiais do parlamento: a documentação de um caso. In: RABELO, F. C. E.; BERNARDES, G. D’Arc (Orgs.). Políticas públicas e cidadania. Goiânia: Cânone Editorial, 2004b. p. 13-27.

As fronteiras da lembrança: memória corporificada, construção de identidades e purificação simbólica no caso de desastre radioativo. Vivência, Natal, UFRGN, n. 28, p. 57-73, 2005.

As celebrações, a memória traumática e os rituais de aniversário. Revista UFG, ano IX, n. 1, p. 12-18, ago. 2007. Disponível em: <http://www.proec.ufg.br/revista_ ufg/agosto2007/index.htm>.

Radiation narratives and illness: the politics of memory on the Goiânia Disaster. Saarbruken, Germany: VDM Dr. Muller Aktiengesellschaft \& Co.KG, 2009a.

Colecionando cartões postais: os lugares constituídos em contexto de isolamento. Visualidades, Revista do Programa de Mestrado em Cultura Visual, Faculdade de Artes Visuais, Goiânia, v. 7, n. 1, jan./jun. p. 214-233, 2009b.

Musealização de eventos críticos: análise da tensão entre múltiplas narrativas de dor. In: TAMASO, I.; LIMA FILHO, M. F. Antropologia e patrimônio cultural: trajetórias e conceitos. Brasília: Associação Brasileira de Antropologia, 2012. p. 497-525.

As oleiras karajá e o modo de fazer ritxoko: o conhecimento circula, expressa identidade e marca território. In: _______. (Org.). Ritxoko. Goiânia: Cânone Editorial, 2014a. (No prelo).

Modos de fazer boneca karajá, circulação do conhecimento e a construção da identidade étnica. Quaderni di Thule XIII, Perugia, Itália, 2014b. (Formato digital).

Entre múltiplos saberes e experiências de sofrimento: instituições, atores sociais e políticas de saúde na gestão do desastre radioativo com o Césio-137 em Goiânia, Goiás. In: FREITAS, L. C. B.; CÁSSIA, C.; SOUZA, R. B. de. Patrimônio cultural da saúde em Goiás: instituições hospitalares, assistenciais, de ensino e de pesquisa. Rio de Janeiro: Fundação Oswaldo Cruz; Goiânia: Ed. UFG, 2014c. (No prelo). 
UNIVERSIDADE FEDERAL DE GOIÁS/NÚCLEO DE ACOMPANHAMENTO DO ACIDENTE RADiOlÓGICO DE GOIÂNIA (NUAC). Proposta de acompanhamento das atividades do núcleo, 1987. (Manuscrito). UFG AFIRMATIVA. Publicação da Assessoria de Comunicação da UFG, n. 4, dez. 2009. Disponível em: <htpps//WWW.yumpu.com/ptdocuments/view/ 12858929/afirmativa-ufg/27>. Acesso em: 18 set. 2014.
VALADARES, I. M. de O.; LIMA, N. C. de (Orgs.). Histórias populares de Jaraguá. Goiânia: CECUP-ICHLUFG, 1983a.

(Orgs.). Histórias populares de Jaraguá: Tereza Bicuda. Goiânia: CECUP-ICHL-UFG, 1983b.

WIEDERHECKER, C. L. Cidade, promessa, exclusão: o Césio-137 em Goiânia. Tese (Doutorado) - Universidade de São Paulo, São Paulo, 1988.

\title{
Reading traces/weaving marks/telling histories: a pathway shaped at the Social Sciences Department, UFG
}

\begin{abstract}
From the perspective of subjective experiences, this essay describes and analyses the intersections between the Centro de Cultura Popular (CECUP), the Anthropological Specialization Courses and the Social Sciences Department (UFG). The work discusses the ways in which the academic practices undertaken by students, professors, and researchers during the $80^{\circ}$ and $90^{\prime}$, and remembered through this text, guide some of the subjects of study and analysis in the following years. Based on the notions of "empreintes", trajectory and social aging, my argument is that the stories framed as "one" experience echoe the Social Sciences Department history and constitute the panel of traces designed on its surface as well.
\end{abstract}

Key words: trajectory, narrative, memory, CECUP, Museu Antropológico (UFG).

\section{Leer pistas/tejer rasgos/contar historias: la configuración de una trayectoria en las Ciencias Sociales, UFG}

\section{Resumen}

A partir de las experiencias subjetivas, este trabajo describe y analiza las intersecciones entre el Centro de Estudios de la Cultura Popular (CECUP), los Cursos de Especialización en Antropología y las Ciencias Sociales de la UFG. Situadas en los años ochenta y noventa del siglo pasado, las prácticas de estudiante, de la enseñanza y de la investigación que aquí recordé informan proyectos y temáticas de estudio en los años que siguieron. El argumento de este artículo, a partir de las nociones de pistas/marcas, de la trayectoria y del envejecimiento social, propone que las historias aquí configuradas como "una" experiencia son eco de la historia misma de las Ciencias Sociales y componen el panel de los rastros aquí diseñados.

Palabras clave: trayectoria, narrativa, memoria, CECUP, Museo Antropológico (UFG).

Data de recebimento do artigo: 30/10/2014

Data de aprovação do artigo: 18/12/2014 